\title{
Fifty-five years of optics as a teaching and research domain at Laval University
}

\section{Roger Lessard}

Roger A. Lessard, "Fifty-five years of optics as a teaching and research domain at Laval University," Proc. SPIE 3831, Sixth International Conference on Education and Training in Optics and Photonics, (16 June 2000); doi: $10.1117 / 12.388708$

SPIE Event: Education and Training in Optics and Photonics (ETOP'99), 1999, Cancun, Mexico 


\title{
Fifty-five years of optics as a teaching and research domain at Laval University
}

\author{
Roger A. Lessard \\ Center for Optics, Photonics and Lasers, Department of Physics, Faculty of Sciences and \\ Engineering, Laval University, Quebec City (Quebec) G1K 7P4 \\ Tel: 418-656-3436; Telec: 418-656-2623; E-mail; ralessard@phy.ulaval.ca
}

\begin{abstract}
Optics has been a designated domain for research since the foundation of the department of physics. One of the first graduate chooses Optics and trained most of the people working in Optics in Canada until 1985 when he retired. The Curriculum of the program in physics and later on in Physics engineering was pointing Optics as an course to take to get the diploma. Laboratories where developed to give to Physicists or Physics Engineers the tools they will need in their career. Nowadays, with the growing importance of Optics, Micro-programs were defined to permit to Mechanical, Electrical and Computer Engineers to acquire a basic knowledge of Physics. Optics Engineering is being developed.
\end{abstract}

Keywords: Optics Program, Physics, Physics Engineering, Optics Engineering, Optics Education

\section{INTRODUCTION}

Laval University (Universite Laval) has been founded in 1663 par François de Montmorency de Laval, the First Bishop coming from France. The University was declared University under the English Regime by Queen Victoria in 1852. Later on Laval University was re-chartered by the Government of Quebec in 1972.

Laval University which is the second oldest University in North America started to educate in sciences by creating in 1907, a School of Survey, then in 1910, a School of Forest Sciences an in 1920, the Superior School of Chemistry. This is in that School of Chemistry that started the Department of Physics in 1937 and the Faculty of Sciences was established on $6^{\text {th }}$ December 1937.

Laval University and its Faculty of Sciences employed Prof. Franco Rasetti to establish in 1937 the Department of Physics. The first students get their degree in Physics in 1944; Albéric Boivin, Fernand Bonenfant, Claude Geoffrion and Georges Hall.

Prof. Rasetti did orient his first students in different fields of Physics.

\section{FIRST PERIOD}

After the formation of the Department of Physics and the training of the first four Physicists, The development of research and graduate studies started.

Albéric Boivin did choose to study electromagnetic waves et most specifically to the study of diffraction of the electromagnetic wave. He got a Master degree in 1949 for an experimental and theoretical study of Soret Zone Plate fabricated on bichromated gelatin. Then he started theoretical studies on diffraction of electromagnetic waves and he was particularly interested to superresolution. 
During this period, a second professor (Dr Guy Lansraux) from France was engaged. Albéric Boivin had a student at the Master level, Mr. Jean Lefaivre, and a student at the Doctorate level, Mr. Réal Tremblay. Guy Lansraux had two students, Mr. Germain Boivin and Mr. Claude Delisle, both at the Doctorate level.

Albéric Boivin and his student, R. Tremblay, got their Doctorate degree in 1960 while Germain Boivin got his in 1961 and Claude Delisle in 1963.

We can say that 1960 was the first milestone for the development of Optics as a teaching and research domain at Laval University. In effect, all the graduate students who get a Doctorate in Sciences became faculty member after one or two years of post-doctorate studies in Rochester or at the Institute of Optics in Paris, France.

\section{OPTICS AS A DISCIPLINE}

Right at the beginning, Optics appeared in the program of Physics on the same level than Atomic Physics, Nuclear Physics, Quantum Mechanics, Mathematical Physics as well as theoretical courses than in laboratories experiments

\section{First group: the LOH.}

In 1966, the Faculty members having Optics as research domain decided to establish a group named: LOH, i.e. 'Laboratoire d'optique et d'hyperfréquence' or in English 'Laboratory of Optics and hyperfrequencies. The Director was Prof. A. Boivin. This group was formed of Prof. A. Boivin, Dr. G. Boivin, Mr. Y. Chassé, Dr. C. Delisle and Dr. R. Tremblay. The LOH got a first supporting grant from National Research Council of Canada in 1968 and was then recognized as a major research center in Canada. Prof. A. Boivin was seeing the importance of Optics and for him, the superresolution was predicted by him as an important achievement for the application of Optics. So, as there was no light sources available as today, a lot of people did not believe in his prediction. He was too far in advance as we can understand today.

In 1970 and after, others joigned the Department of Physics; Dr. Marguerite-Marie Denariez-Roberge, Dr. Gabriel Bédard, Dr Henri H. Arsenault, Dr. John Lit and later, Dr. Jerald F.Izatt.

\section{Second group: LROL}

Dr Réal Tremblay became the Director or the $\mathrm{LOH}$ and proposed a name change in 1971 . The laboratory became the LROL know in French as 'Laboratoire de recherche en optique et laser' and in English as the 'Laboratory for Research in Optics and laser'. This Laboratory, one of the first Research Center at Laval University was officially recognized by the Faculty of Sciences, the University Council and the Ministry of Education of the Government of Quebec as an important instrumental for the development of knowledge and for training of specialists Quebec will needed in the future. LROL was seen as the best place to do research and train graduate students for many years.

This group enlarged in 1972 by the addition of new members; Dr. Pierre-André Bélanger, Dr. See Leang Chin, Dr. Roger A. Lessard and Dr. Andrej Zardewsky.

Due to the leadership of Dr. See Leang Chin, Director from 1981 to 1987, the LROL got a strong support from the National Research Council of Canada and he motivated a study made by the Canadian Association of Physicists on the importance of having a National Institute in Optics and its location. This study recommended to create a National Institute of Optics and to put this Institute in Quebec City since that most of the research in Optics was and is done in Quebec area

\section{Increasing importance of Optics}

Government of Quebec through his Ministry of Sciences and Technology decided to promote employment of Scientists in the area that was seen as very important for Quebec futur. Many proposals were submitted and one of 
the first accepted was a structurant grant to develop Optics and increase the capability of the LROL. This structurant grant was given to four professors of the department of physics, members of the LROL. This group leaded by Prof. R. Tremblay was regrouping Prof. Henri H. Arsennault, Prof. Claude Delisle and Prof. Roger A. Lessard. This grant permitted to buy new instruments and more important to recruit 5 new researchers who will become after a certain period Faculty members of the Department of Physics.

Following this new grant, Optics was seen as a enabling domain that we will find in many other areas. Consequently, the dean of the Faculty of Sciences and Engineering with professors in LROL did work to obtain for Laval University, an industrial chair paid jointly by the NSERC-Natural Science and Engineering Research Council and Quebec Telephone having for objective the development of Optical Communications. The Dean decided in 1988 to establish this industrial chair in the Department of Electrical Engineering since this Department had just recently started a research group called LROS- Laboratory for Research on Oscillators and Systems. Consequently, the unification of the LROS and the Industrial Chair gave birth to the group recognized as 'COPM- Communications optiques et métrologie' (Optical communication and Metrology).

We had then inside de Faculty of Sciences and Engineering, two research groups related to research in Optics.

\section{Third group: COPL}

In 1989, Prof. Roger A. Lessard became director of the LROL. He organized meetings with all researchers interested in Optics, met the Dean of the Faculty of Sciences and Engineering, the Directors of the Department of Physics and the Department of Electrical Engineering, obtained some financial support from the Vice-Dean for Research of the Faculty and the Vice-Rector for research of the University. We formed then the COPL-Centre d'optique, photonique et laser (Center for Optics, Photonics and Lasers).

It was the beginning of a new era where we saw 13 professors and researchers based in the Department of Physics connected with the 4 professors in the Department of Electrical Engineering, about 80 graduate students and a technical and clerical staff.

The COPL was then one of the largest group of researchers having Optics as discipline. Following the formation of this new entity recognized by the Faculty of Sciences and Engineering, the University Council, the COPL got in 1990 a five years grant from the Quebec granting body 'FCAR' of $285 \mathrm{k} \$$ per year to run this center.

This year, 1999, ten years after the foundation of COPL, Prof. Michel Têtu, director, establishes the Canadian Institute for Photonics Innovations - CIPI, a Canadian based Center of Excellence, comprising most of the professors of the COPL and members coming from 21 other universities all over Canada, some industries and some governmental laboratories.

\section{TRAINING IN OPTICS}

\section{First Curriculum of Physics:}

As we have seen from the evolution of Optics as a discipline at Laval University, the curriculum must have emphasized a little this part of Physics.

So, until 1966, teaching of Optics was done through a basic course and some laboratories during the first year followed by a course called Physical Optics I in third year. There was also some laboratories where students were doing some optical measurements.

\section{Second Curriculum of Physics:}

After the formation of the $\mathrm{LOH}$, more professors were available to do the training in Optics. Consequently, although the undergraduate courses remained the same, some graduate courses appeared. They do emphasize courses on 
advanced diffraction, holography and lasers were started to complete the existing courses on Advanced Electromagnetism and Advanced Mathematical Physics.

At this time, there was no difference between the Physics Program and the Engineering Physics Program regarding their Optics contents.

\section{Curriculum in Physics and Physics engineering during the LROL period.}

At this time, changes occurred in Education in Province of Quebec were all in place. Primary school for 6 years, secondary school for 5 years, a new college level called CEGEP was established for 2 years and most of the programs at university went from 4 to 5 years. So, the Physics program went to 3 years but the Physics Engineering program as all Engineering programs was kept on a 4 year basis.

At the under graduate level in Physics, all old first year courses were transferred to CEGEP and we kept 2 courses in the second and third year of the Program. It was Physical Optics a mandatory course and Advanced Optics an optional course. Those courses were complemented by a set of laboratories experiments.

Physics engineering was completely remodeled and it was made of an obligatory core plus optional specialization. Of course, one of those specialization was Optics. This specialization was containing a mandatory course for Physics Engineers, Instrumental Optics and courses like Guided Optics, Optics for Communications, Physical Optics, Advanced Optics.

Graduate level saw the development of courses like Lasers I and II, Holography. Fourier Optics, Optical Information Processing, Quantum Optics, Experimental Optics I and II, Interference and Measurements, Lens Design, Nonlinear Optics.

\section{Changes occurring due to the foundation of COPL.}

Due to the venue of a new player in the Optics domain, the Department of Electrical Engineering, some adaptation were to be done.

For the programs in Physics and Physics Engineering at undergraduate level, there was no real change. However, the program of Electrical Engineering did add some courses related to Optics like one on Optics Materials, Diode lasers and applications.

Also, some changes happen in the graduate courses. Of course being 18 professors coming from two departments which delivers diploma in Physics, Physics Engineering for the Department of Physics and in Electrical Engineering, Computer Engineering for the Department of Electrical and Computer Engineering can give lecture with different perspective. At the graduate level, the Faculty of Advanced Studies is delivering diploma of M.Sc.(Physics-Optics), Ph.D. (Physics-Optics) for the Department of Physics and M.Sc.A. (Electrical Engineering - Optics), D.Sc. (Electrical Engineering - Optics) for the Department of Electrical and Computer Engineering.

\section{Actual curricula for Physics, Physics Engineering, Electrical and Computer Engineering.}

We had recently a reshaping of all scientific and engineering programs in our Faculty of Sciences and Engineering. We have the chance of having in the same Faculty, programs of sciences and programs of engineering. It was an historical decision made by the Faculty members that decided to keep under a unique roof, pure and applied sciences. This is facilitating cooperation between pure and applied scientists.

Actually, the Department of physics which is in charge of the training of Physicists and of the basic training of the Physics Engineers, is running a 3 year program for Physics and a 4 year program for Physics Engineering.

First of all, let us have a look at the Optics courses offered inside the program of Physics. 
Baccalaureat in Sciences (B.Sc. (Physics))

\begin{tabular}{ll} 
Mandatory courses & \multicolumn{1}{c}{$\quad 75$ credits } \\
PHY-10484 & Introduction to Astrophysics \\
PHY-10486 & Mathematical Physics II \\
GML-21452 & Material Sciences \\
PHY-10493 & Quantum Physics \\
PHY-10491 & Waves and Linear Systems \\
PHY-10492 & Classical Mechanics II \\
GEL-19962 & Signals Analysis \\
IFT-17582 & Algorithm and programming \\
CHM-10099 & Physical Chemistry I \\
PHY-20923 & Experimental Physics III \\
PHY-10508 & Statistics Physics \\
PHY-17323 & Solid State Physics \\
PHY-20925 & Experimental Physics V
\end{tabular}

Optional courses : 15 credits PHY-20912 Photonics and Lasers GPH-21029 Lasers and Applications PHY-17448 Dynamic Systems and Chaos ENP-19994 Training in Administration Class II PHY-21465 Practicing in Physics

+ Some others available

Optics courses content ${ }^{1}$ PHY-10502 Optics Credit: $3 \mathrm{cr}$ Interferences et interferometers. Diffraction: Fraunhofer, Fresnel, Gratings. Polarization: representation, Jones matrices. Anisotropic media. Dispersive media and optical constants. Geometrical Optics : Optical Systems, image formation and aberrations. Applications.

Option :

PHY-20912 Photonics and Lasers Credit: $3 \mathrm{cr}$ Electromagnetic Waves in crystals. Integrated Optics. Planar Waveguides and Optical fibers. Acousto-optics and Nonlinear effects. Light Diffusion by acoustic waves. Fadiometry and photometry. Lambert's law. Detectors. Laser. Gaussian beam propagation.

GPH-21029 Lasers et applications Credit: $3 \mathrm{cr}$ Model of the Classical oscillator and stimulated emission. Bipolar electric transitions. Evolution equations. Laser amplifier. Optical cavities and retroaction. Laser beams and resonators. Laser applications in treatment of materials., teledetection, telecommunications and medicine.

GPH-21335 Optical waveguides Credit: $4 \mathrm{cr}$ Guides optics. Electromagnetic theory of plane waveguide (TE-TM); geometrical model; coupling between two plane waveguides; introduction to integrated optics. Laboratory of integrated optics: fabrication et characterization of a plane waveguide; study of the coupling between two guides. Optical fiber: propagation of an impulse in a dispersive medium; electromagnetism theory of the index step fiber; introduction to communications using an optical fiber; introduction to optical fibres sensors. Laboratory on optical fiber: characterization of monomode and multimode fibers; building of a communication system using an optical fiber; fabrication of optical fiber sensor.

\section{Baccalaureat in Applied Sciences or Engineering (B.Sc.A.(Physics Eng.) or B.Eng); Length 8 terms}

Mandatory courses: $\quad 105$ credits

GLG-20699 Introduction to earth sciences

PHY-10485 Mathematical Physics I
PHY-17033 Physics Engineering Practice

PHY-10486 Mathematical Physics II 
GMC-10284 Technical thermodynamics

\section{Sub-total: 16 credits}

PHY-10487 Mathematical Physics III

PHY-18757 Electromagnetism

GEL-21148 Design elements

Sub-total: 31 credits

GMC-10302 Techniques of Mechanics II

GMC-10292 Mechanics of fluids I

PHY-10501 Electromagnetic Waves

Sub-total: 47 credits

PHY-10493 Quantum Physics

GEL-16132 Circuits

One language course

Sub-total: 63 credits

STT-20694 Probability for Engineers

Sub-total: 69 credits

GPH-14308 Atomic and Nuclear Physics

PHY-17323 Solid state Physics

Sub-total: 81 credits

GPH-17443 Project I

GPH-18756 Advanced Laboratories

Sub-total: 90 credits

GPH-17444 Project II

ECN-15452 Economic Analysis and Engineering

One complementary course

Sub-total: 102 credits

GMC-10282 Drawing for Engineer or GPH-20391 Stage Physics Engineering

Sub-total: 105 credits

Specialization courses for Photonics ans Telecommunications ${ }^{1}: \quad 15$ credits

Take one of the following courses: 3 credits

GEL-19962 Signal analysis

GPH-21334 Element of photonics

Take other credits among the following courses ${ }^{1}$ :

GEL-10280 Digital Communications

GEL-16120 Communication Systems

GEL-17982 Optical Communications

GPH-21335 Optical Waveguides

Courses content related to Optics ${ }^{1}$ :

PHY-10491 Waves and Linear Systems; Credit: 3 cr

Free Oscillations of systems with one or more degrees of freedom. Modes. Continuous Systems. Oscillations forcées

Resonance. Coupled Oscillators. Progressive Waves. Phase velocity. Dispersion. Reflection. Modulation, pulsations, wave paquets. Group Velocity. Waves in two and three dimensions.

GPH-14306 Instrumental Optics

Credit: $4 \mathrm{cr}$

Geometrical optics and aberrations. Optical Components : objective, doublet, ocular. Instruments. Eye. Inetgrated

Optics. Optical fibers. Photometry. Radiometry. Sources. Detectors. 
GPH-21334 Element of photonics Crédit: $4 \mathrm{cr}$

Laser: theory of amplificators and basic of lasers; Resonance mode and stability, propagation of a gaussian beam, $\mathrm{ABCD}$ matrix; review of the main lasers and of their applications (gaz, solid, semi-conductor, etc.). Laboratory with lasers: experimental study of $\mathrm{CO}_{2}$ lasers; characterization of a laser beam and study of its propagation through optical systems ; surface treatment and laser welding. Electro-optics : anisotropic medium'; electron and magneto-optics, acouto-optics; introduction to nonlinear optics. Laboratory of Electro-optics: mode-locking of a $\mathrm{CO}_{2}$ TEA Laser using acousto-optics modulation; study of spatial autofocalization; liquid crystals manipulation et application.

GEL-17982 Optical Communications Credit: $3 \mathrm{cr}$

Introduction: historic, analogic and digital communications. Properties of Optical materials. Planar Waveguides. Optical fibers: propagation modes, attenuation, dispersion, fabrication. Sources: electroluminescent diode, Semiconductor lasers, E/O conversion. Photodetector: PIN, APD, Connetics. Systems for optical communications: signal to noise ratio. Measurement Apparatus. Long distance Télécommunications. Local and metropolitan networks. Optical amplifiers. Coherent optical communications. Communications with solitons. Optical fiber sensors. Bibliography:

SENIOR, J. Optical Fiber Communications: Principles and Practice, 2nd Ed., Prentice-Hall, 1992.

SALEH, B.E.A., TEICH, M.C. Fundamentals of Photonics, Wesley-Interscience, 1991.

\section{Baccalaureat in Applied Sciences (B.Sc.A. (Electrical Eng.) or B.Eng.); Length 8 terms}

\begin{tabular}{ll}
\multicolumn{2}{l}{ Mandatory courses } \\
GIF-10279 & Logic Circuits \\
GML-10463 & Materials for Engineers \\
MAT-19961 & Matrix Calculus \\
GEL-21148 & Elements of design \\
MAT-18996 & Numerical Analysis for Engineers \\
GEL-19962 & Signal analysis \\
IFT-19966 & Algorithms for Engineers I \\
GEL-16142 & Electronics of integrated components \\
GEL-21404 & Design II \\
GEL-15217 & Electrical Machinery \\
GEL-19964 & Signals and discrete systems \\
ECN-15452 & Economic analysis in Engineering \\
GEL-21405 & Design III \\
GEL-10255 & Physics of electronic components \\
GEL-21406 & Design IV
\end{tabular}

Optionnal courses: $\quad 23$ credits

A- LISTE A

Take at least one course in the following list:

GEL-17598 Industrial control

GEL-17703 Introduction to signal processing

Specialization in communications:

GEL-10280 Digital communications

GEL-17982 Optical communications

$\begin{array}{ll}\text { IFT-19965 } & \text { Programming in C++ with Unix } \\ \text { MAT-10363 } & \text { Mathematics for Engineers I } \\ \text { GEL-16132 } & \text { Circuits } \\ \text { MAT-10364 } & \text { Mathematics for Engineers II } \\ \text { GIF-16116 } & \text { Structure of Computers and applications } \\ \text { GEL-19879 } & \text { Electromagnetism } \\ \text { GEL-15216 } & \text { Electrotechnique } \\ \text { GEL-19963 } & \text { Systems and linear command } \\ \text { STT-20694 } & \text { Probability for Engineers } \\ \text { GEL-16138 } & \text { Electronics of discrete components } \\ \text { GEL-16120 } & \text { Communications Systems } \\ \text { GEL-19881 } & \text { Transmission of Electromagnetic waves } \\ \text { GMN-16209 } & \text { Health and Security in Engineering II } \\ \text { SOC-17707 } & \text { Sociology of technological innovation } \\ \text { GEL-21395 } & \text { Training in entreprises I }\end{array}$

IFT-19965 Programming in C++ with Unix

MAT-10364 Mathematics for Engineers II

GEL-19879 Electromagnetism

Electrotechnique

STT-20694 Probability for Engineers

GEL-16138 Electronics of discrete components

GEL-19881 Transmission of Electromagnetic waves

SOC-17707 Sociology of technological innovation

GEL-21395 Training in entreprises

Formation in entreprises

Take at least two credits among the following courses

GEL-21407 Training in entreprises II

GEL-21408 Training in entreprises

Management

Take at least one course among the following:

CTB-21381 Accountability I

DRT-19457 Law, ethics and engineering

DRT-18075 Legal aspects of businesses

GSO-19217 Management of technology 
MNG-11884 Management

RLT-15493 Introduction to industrial relations

management.

SIO-19224 Control of information systems.

Foreign languages:

Take one course among the list:

ANL-14959 Oral and written English II

ANL-14961 Oral and written English IV
MRK-19222 Principles of marketing

RLT-17043 Administrative and human aspects of

\section{Graduate studies at COPL:}

The Center for Optics, Photonics and Lasers is a research center. Those taking graduate studies will get their diploma ether from the Department of Physics or the Department of Electrical and Computer Engineering. As all the students will get a diploma having an Optics flavor, most of them will take the following slate of courses.

Master level: $\quad 45$ credits (courses 13 credits; research 32 credits)

a) Physics:

General courses:

PHY-62874 Science and Laser Technology $\quad$ PHY-64199 La science de l'image

Specialized courses:

PHY-60650 Elements of Fourier Optics

PHY-62871 Optical information Processing

PHY-62878 Nonlinear Optics

PHY-64198 Elements of optical Design

PHY-65087 Holography and diffractive optics
PHY-60663 Integrated Optics and Optical Fibers

PHY-62876 Interferometry et coherence

PHY-64108 Lasers dynamics

PHY-64434 Optical fibres and nonlinear effects

PHY-65837 Bases of optics

\section{b) Electrical and Computer Engineering:}

General courses:

GEL-64324 Redaction and Scientifc presentation

GEL-64458 Selected readings in Elect. Eng. II

Complementary course: 3 credits (One of the following course)

GSO-63582 Projects management

MNG-64250 Principles of management

Doctorate level: $\quad 90$ credits (courses 9 credits; research 81 credits)

a) Physics:

There is a predoctorate exam to ensure that the candidate has the required qualification.

Courses in Optics:

PHY-60650 Elements of Fourier Optics

PHY-62871 Optical information Processing

PHY-62878 Nonlinear Optics

PHY-64198 Elements of optical Design

PHY-65087 Holography and diffractive optics

PHY-60663 Integrated Optics and Optical Fibers

PHY-62876 Interferometry et coherence

PHY-64108 Lasers dynamics

PHY-64434 Optical fibres and nonlinear effects

PHY -65837 Bases of optics

\section{b) Electrical and Computer Engineering:}

There is a predoctorate exam to ensure that the candidate has the required qualification.

Courses in Optics:

GEL-64045 Semi-conductor Lasers

PHY-64554 Laser Spectroscopy

GEL-64943 Detection and evaluation

PHY-60663 Integrated Optics and optical fibers

PHY-64108 Lasers dynamics

PHY-64198 Elements of optical design

GEL-64481 Introduction to signal processing
GEL-65423 Components made of opical fibers

GEL-64457 Optical communication systems

PHY-65837 Bases of optics

PHY-62878 Nonlinear optics

PHY-64434 Optical fibers and nonlinear effects

GEL-64478 Optical communications

EL-64483 Technology related to hyperfrequencies 
GEL-64486 Digital communications

As we can see those two departments are offering a good slate of courses that permits to training very well qualified specialists for canadian universities, governmental laboratories and industries.

\section{SPECIALISTS FORMED}

To complete this presentation, let us have a look to a graph showing the evolution of Optics at Laval University between 1968 and 1998 .

Figure 1 shows that in 1968, there was 5 Professors, 12 graduate students and they published 7 papers. In 1972, at the formation of the LROL, there was 12 professors, 37 graduate students and they made 33 publications. In 1989, at the beginning of the COPL, the center was having 17 professors, 85 graduate students and they publishes 45 papers. At the end of 1997-1998, we were 17 professors for 95 graduate students and 89 papers were published.

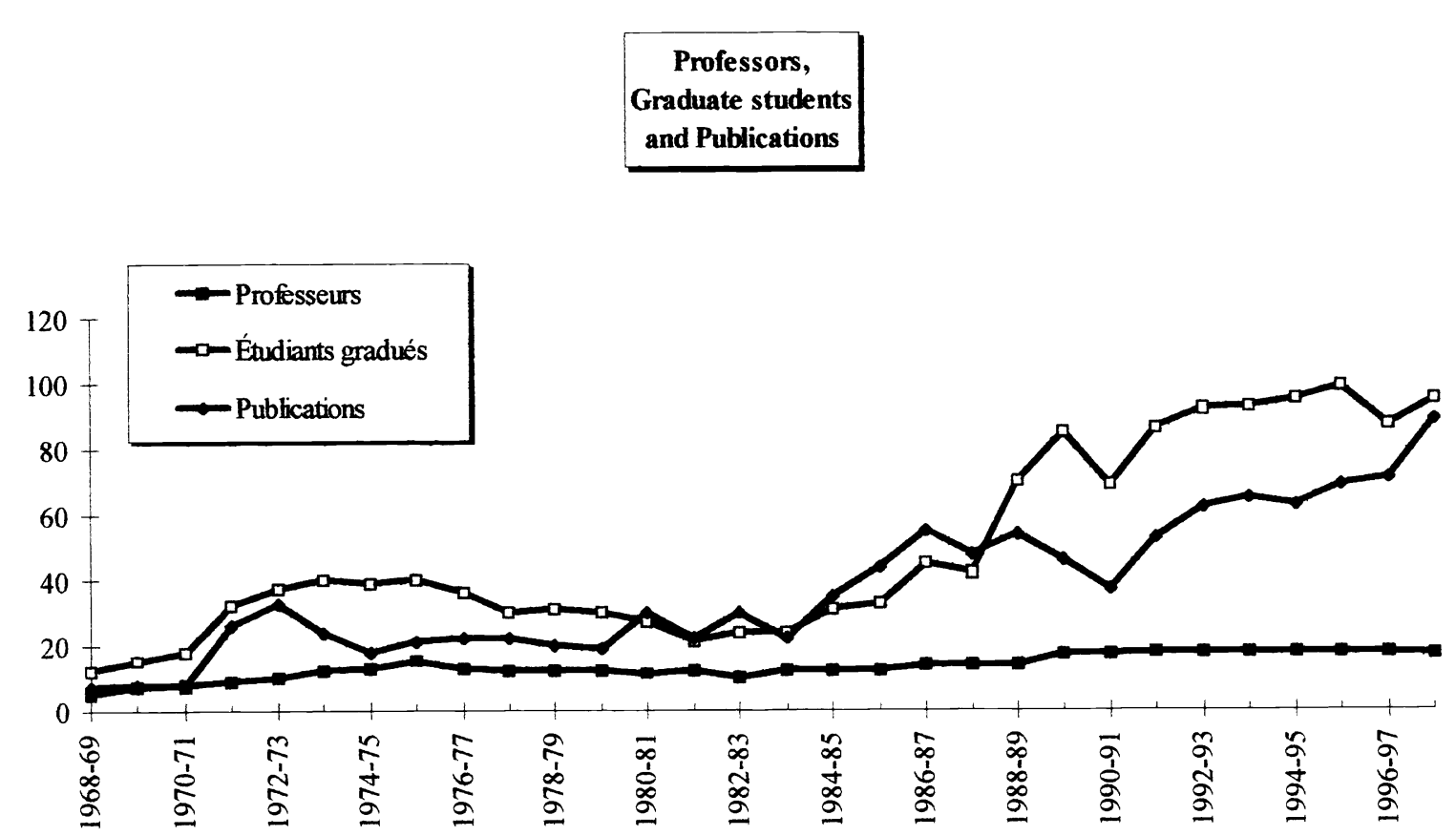

Figure 1: Evolution of the number of professors, number of graduate students and the number of publications by year. LOH: 1966 to 1971; LROL: 1971 to 1989; COPL: 1989 until now.

The number of diploma given is shown in Figure 2.

In 1968, the LOH was responsible for 2 Doctorate and 3 Master degrees. The first year of LROL, 3 students get their degree; 1 Doctorate and 3 Masters. In 1989, we got many new students and the one at the master level decided to take a Ph.D. Consequently, no student got a Ph.D. but 18 got a Master. If we look at the evolution of the number of graduates students who got a degree per year it is easily seen that there is a great variation from one year to the other.

However, it is important to note that Laval University did deliver D.Sc. and Ph.D. diploma to 121 students between 1967-1968 and 1996-1998. During the same period, 221 students get a Master in Sciences (Optics). 


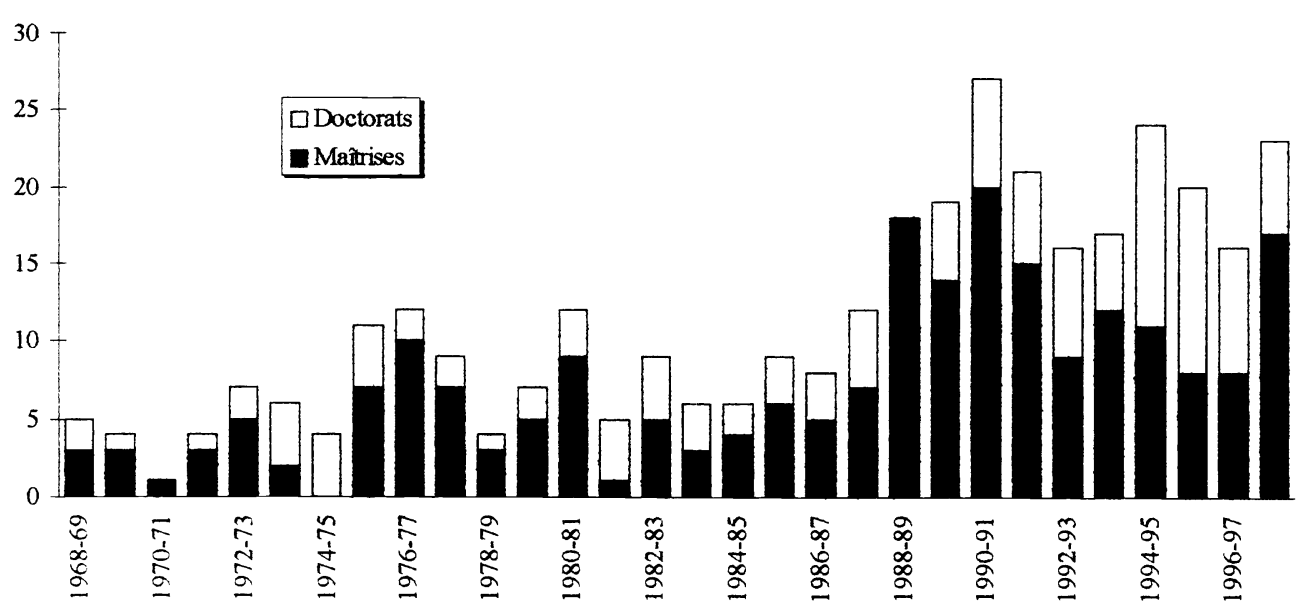

Figure 2: Number of Students who got a Doctorate in Sciences (before 1973), a Ph.D. or a Master degree at Laval University per year from 1968 to may 1998.

\section{CONCLUDING REMARKS}

We have seen in this presentation, how Optics as a research and teaching domain at Laval University changes in the last 55 years 126 candidates received a D.Sc. or Ph.D. and 227 others got a M.Sc. or M.Sc.A. from Laval University. Some of those 453 graduates received both diploma from Laval University and we can find them in Canada, France, Belgium, Brazil, China, Columbia, Japan, Mexico, Morocco, United States of America, Iran, Iraq, some African Counties, etc.

Due to the importance which is taking Optics in our everyday life, we are now restarting our old project of having an Engineering Optics program. We recently build up Micro-programs that will permit to Mechanical Engineers, Electrical Engineers, Computer Engineers and others to get some basic knowledge of optics in such a way that they can rapidly contribute in industries which are optics related.

The development of a program of Optics Engineering must be approved by the 'CREPUQ - Conseils de Principaux et Recteurs des Universités du Québec' (Council of Principals and Rectors of Universities of the Province of Quebec as well as the 'OIQ - Ordre des Ingénieurs du Québec (Guild of Professional Engineers of Province of Quebec) before starting it. We hope that this approval will not be too long. 
${ }^{T}$ Definition of the abbreviations used to defined the courses:
ANL = Courses defined for the program of English Language
$\mathrm{CHM}=$ Courses defined for the program of Chemistry
CTB = Courses defined for the program of Accountability
DRT = Courses defined for the program of Law
ECN = Courses defined for the program of Economics
IFT = Courses defined for the program of Informatics
GEL = Courses defined for the program of Electrical Engineering
GIF = Courses defined for the program of Computer Engineering
GLG = Courses defined for the program of Geology
GMC = Courses defined for the program of Mechanical Engineering
GML = Courses defined for the program of Metallurgic Engineering
GMN = Courses defined for the program of Mining Engineering
$\mathrm{GPH}=$ Courses defined for the program of Physics Engineering
GSO = Courses defined for the program of Administration of operation
MAT = Courses defined for the program of Mathematics
PHY = Courses defined for the program of Physics
RLT = Courses defined for the program of Industrial Management
SIO = Courses defined for the program of Administration of Information of organisation
SOC $=$ Courses defined for the program of Sociology
STT = Courses defined for the program of Stastistics 